\title{
Biliary Anomalies in Patients With HNF1B Diabetes
}

\section{Kettunen, Jarno L. T.}

2017-06

Kettunen , J L T , Parviainen , H , Miettinen , P J , Färkkilä , M , Tamminen , M , Salonen , P , Lantto , E \& Tuomi , T 2017 , ' Biliary Anomalies in Patients With HNF1B Diabetes ' , Journal of Clinical Endocrinology and Metabolism , vol. 102 , no. 6 , pp. 2075-2082 . https://doi.org/10.1210/jc.2017-

http://hdl.handle.net/10138/198893

https://doi.org/10.1210/jc.2017-00061

unspecified

publishedVersion

Downloaded from Helda, University of Helsinki institutional repository.

This is an electronic reprint of the original article.

This reprint may differ from the original in pagination and typographic detail.

Please cite the original version. 


\title{
Biliary Anomalies in Patients With HNF1B Diabetes
}

\author{
Jarno L. T. Kettunen, ${ }^{1,2}$ Helka Parviainen, ${ }^{3}$ Päivi J. Miettinen, ${ }^{4}$ Martti Färkkilä, ${ }^{5}$ \\ Marjo Tamminen, ${ }^{6}$ Pia Salonen, ${ }^{7}$ Eila Lantto, ${ }^{3}$ and Tiinamaija Tuomi ${ }^{1,2,8}$ \\ ${ }^{1}$ Department of Endocrinology, Abdominal Centre, Helsinki University Hospital, Helsinki 00029, Finland; \\ ${ }^{2}$ Folkhalsan Research Center; and Research Programs Unit, Diabetes and Obesity, University of Helsinki, \\ Helsinki 00014, Finland; ${ }^{3}$ HUS Medical Imaging Center, Radiology, University of Helsinki and Helsinki \\ University Hospital, Helsinki 00029, Finland; ${ }^{4}$ Children's Hospital, University of Helsinki, and Helsinki \\ University Hospital, Helsinki 00029, Finland; ${ }^{5}$ University of Helsinki, Department of Gastroenterology, \\ Abdominal Centre, and Helsinki University Hospital, Helsinki 00029, Finland; ${ }^{6}$ Department of Internal \\ Medicine, Central Hospital of Kymenlaakso, Kotka 48210, Finland; ${ }^{7}$ Department of Pediatrics, Central \\ Hospital of Päijät-Häme, Lahti 15850, Finland; and ${ }^{8}$ Institute for Molecular Medicine Finland, University of \\ Helsinki, Helsinki 00014, Finland
}

Context: The clinical spectrum of organogenetic anomalies associated with HNF1B mutations is heterogeneous. Besides cystic kidney disease, diabetes, and various other manifestations, odd cases of mainly neonatal and posttransplantation cholestasis have been described. The biliary phenotype is incompletely defined.

Objective: To systematically characterize HNF1B-related anomalies in the bile ducts by imaging with magnetic resonance imaging (MRI) or magnetic resonance cholangiopancreatography (MRCP).

Setting and Patients: Fourteen patients with HNF1B mutations in the catchment area of the Helsinki University Hospital were evaluated with upper abdominal MRI and MRCP. Blood samples and clinical history provided supplemental data on the individual phenotype.

Main Outcome Measure(s): Structural anomalies in the biliary system, medical history of cholestasis, other findings in abdominal organs, diabetes and antihyperglycemic treatment, hypomagnesemia, and hyperuricemia.

Results: Structural anomalies of the bile ducts were found in seven of 14 patients $(50 \%)$. Six patients had choledochal cysts, which are generally considered premalignant.

Conclusions: Structural anomalies of the biliary system were common in HNF1B mutation carriers. The malignant potential of HNF1B-associated choledochal cysts warrants further studies. ( $\mathrm{J}$ Clin Endocrinol Metab 102: 2075-2082, 2017)

$\mathbf{H}$ epatocyte nuclear factor $1 \mathrm{~B}(\mathrm{HNF} 1 \beta)$ is a key regulator of mammalian organogenesis that is particularly required for specification of the pancreas and other organs derived from the ventral endoderm (1-5). Autosomal-dominantly inherited mutations in the $H N F 1 B$ gene lead to a spectrum of clinical manifestations. HNF1B mutations rank as the most common monogenic cause of kidney and urinary tract anomalies, with renal function ranging from normal to end-stage

ISSN Print 0021-972X ISSN Online 1945-7197

Printed in USA

Copyright (C) 2017 Endocrine Society

Received 6 January 2017. Accepted 14 March 2017

First Published Online 17 March 2017 renal disease (6), but kidneys can, nevertheless, appear normal in imaging studies (7). Approximately half of patients with $H N F 1 B$ mutations develop maturity-onset diabetes of the young (MODY) at an age ranging from the neonatal period to adulthood, apparently as a result of pancreatic hypoplasia and impaired insulin secretion, in combination with hepatic insulin resistance (7-11). The heterogeneous extrarenal manifestations also include hypomagnesemia (12), hyperuricemia, early-onset gout

Abbreviations: ALT, alanine aminotransferase; APBJ, anomalous pancreaticobiliary junction; $B D C$, bile duct cyst; ERCP, endoscopic retrograde cholangiopancreatography; $\mathrm{HbA1C}$, glycosylated hemoglobin; HNF1 $\beta$, hepatocyte nuclear factor 1B; MODY, maturity-onset diabetes of the young; MRCP, magnetic resonance cholangiopancreatography; MRI, magnetic resonance imaging. 
$(13,14)$, genital malformations (15-17), elevated liver enzymes $(14,18)$, impaired exocrine pancreatic function (19), and increased parathyroid hormone levels with reduced urinary calcium excretion (20). In addition, larger microdeletions in chromosome $17 \mathrm{q} 12$ harboring HNF1B result in neurologic and behavioral symptoms (21). De novo mutations occur in approximately half of the affected persons (9).

HNF1 $\beta$ is involved in biliary system organogenesis, and conditional deletion of HNF1B in mice leads to severe jaundice, a paucity of small intrahepatic bile ducts, and abnormalities of the gallbladder (22). In humans, data on the possible biliary or hepatic clinical phenotype of $H N F 1 B$ disease are scarce (23-25). Seven case reports have presented patients with either cholestasis or mainly cholestatic liver function tests (25). A few liver biopsies in neonates with cholestasis showed a paucity of bile ducts and ductal plate malformations with duct dysplasia (23-26). Electron microscopy revealed cholangiocytes with fewer primary cilia in biopsies from three adults whose routine liver pathology appeared normal (27). Bile duct imaging is rare in patients with $H N F 1 B$ disease. In endoscopic retrograde cholangiopancreatography (ERCP), one patient had extrahepatic biliary atresia that was confirmed by surgery, and on magnetic resonance imaging (MRI), one patient had slightly dilated intra- and extrahepatic bile ducts $(25,28)$. A few studies provide a limited number of patients who have undergone abdominal MRI $(11,28)$. No study has specifically focused on bile duct imaging.

Here, by use of contrast-enhanced MRI and magnetic resonance cholangiopancreatography (MRCP), noninvasive imaging modalities for hepatic and pancreaticobiliary pathologies, we report biliary abnormalities in patients with HNF1B mutations.

\section{Patients and Methods}

In the catchment area of Helsinki University Hospital, 14 patients from the Botnia Study (www.botnia-study.org) or the FinnMODY Study (www.botnia-study.org/finnmody) with HNF1B mutations underwent upper abdominal MRI and MRCP imaging as part of their clinical follow-up. The Botnia Study has been recruiting families with diabetes from Finland since 1990, and its extension, the FinnMODY Study, has been recruiting patients with diagnosed or possible MODY, as well as their family members, since 2014. The studies followed the principles of the Declaration of Helsinki and were approved by the local ethics committee, with informed consent from all study participants.

Nine patients had a whole-allele deletion of $H N F 1 B$, and five patients (nos. 3, 4, 5, 6, and 13) had heterozygous intragenic mutations. The intragenic mutations comprised a splice site mutation in one patient, a nonsense mutation in another patient, and nonconservative missense mutations in three patients.

Of the 14 patients ( 11 females, three males; age 10 to 68 years at imaging), 13 were diagnosed with diabetes at a median age of 23 years (range, 6 to 54 years; one patient was diagnosed during posttransplantation immunosuppressive treatment). One remained normoglycemic at the age of 22 . Eight patients were treated with insulin, and the rest used no antihyperglycemic medication (Table 1). Data for glycosylated hemoglobin $(\mathrm{HbA} 1 \mathrm{c})$, serum or plasma concentration of alanine aminotransferase (ALT), uric acid, magnesium, creatinine, and cystatin C came from hospital records or the Botnia and FinnMODY Studies. Glomerular filtration rate was estimated in adults by the Chronic Kidney Disease Epidemiology Collaboration equation on the basis of creatinine only, and in children by the Chronic Kidney Disease in Childhood (CKiD) Schwartz equation on the basis of creatinine, blood urea nitrogen, and cystatin C.

Two authors (H.P. and E.L.) interpreted the MRI scans performed from 2003 to 2016 to evaluate the morphology of the biliary system and other abdominal organs. Cystic or fusiform dilatations of the bile ducts [bile duct cysts (BDCs), also known as choledochal cysts] were grouped according to the Todani classification, if applicable (29). All scans were performed with 1.5-T whole-body scanners; gadolinium-enhanced sequences were available in 12 and MRCP sequences in 11 patients. In addition, genital morphology of female patients was evaluated by MRI (nine patients), transabdominal ultrasonography (one patient), or abdominal computed tomography scan (two patients), depending on availability. Table 1 demonstrates the imaging summary of the patients.

The genetic testing included next-generation sequencing confirmed with direct sequencing and/or multiplex ligationdependent probe amplification dosage analysis of the $H N F 1 B$ gene in two service laboratories (the Molecular Genetics Laboratory in Exeter, United Kingdom, or the Genome Center of Eastern Finland). The genetic diagnosis of one patient with a whole-gene deletion was made through molecular karyotyping analysis performed at the laboratory of the Helsinki University Hospital.

\section{Results}

Seven of the 14 patients demonstrated bile duct anomalies on MRI (Figs. 1-2; Table 1). Five patients had varying types of BDCs in the extrahepatic bile ducts and gallbladder, whereas one patient had a 25 -mm-wide intrahepatic BDC communicating with the left main hepatic duct (Fig. 1). In two patients (nos.12 and 14), we observed small diverticula in the wall of the gallbladder fundus consistent with adenomyomatosis. Patient no. 1 had undergone a BDC resection and Roux-en-Y hepaticojejunostomy at the age of 12 years for an incidental BDC, and although slight widening of the proximal intrahepatic bile ducts could be detected in the preoperative MRI scan (Fig. 1), in the postoperative MRI scans, the intrahepatic finding was normal (data not shown). In addition, patient no. 13 had experienced occasional episodes of unspecific upper abdominal pain before receiving a kidney transplantation at the age of 30 , but profound abdominal symptoms with cholestatic liver function tests emerged after transplantation. Posttransplantation imaging revealed moderate dilatation of extrahepatic and 


\section{Table 1. Patient Clinical Characteristics and Imaging Findings}

\begin{tabular}{|c|c|c|c|c|c|c|c|c|}
\hline 1 & $12(\mathrm{~F})$ & $\mathrm{EH} \mathrm{BDC}$ & $\mathrm{N}$ & Tail, body & Multiple cysts & No & $\begin{array}{c}\text { Bicornuate } \\
\text { unicollis }\end{array}$ & None $^{c}$ \\
\hline 2 & $14(\mathrm{M})$ & $\mathrm{N}$ & $\mathrm{N}$ & Tail, body & One cyst & No & - & Combined \\
\hline $3^{d}$ & $10(F)$ & $\mathrm{N}$ & $\mathrm{N}$ & N & Multiple cysts & Mild $^{e}$ & $\mathrm{~N}$ & None \\
\hline 4 & $18(F)$ & $\mathrm{EH} B D C$ & $\mathrm{~N}$ & Tail, body & Multiple cysts & Moderate & $\begin{array}{c}\text { Bicornuate } \\
\text { unicollis }\end{array}$ & None \\
\hline 6 & $44(F)$ & $\mathrm{N}$ & $\mathrm{N}$ & Tail & Multiple cysts & Severe $^{f}$ & $\mathrm{~N}$ & $\begin{array}{l}\text { Intermediate- } \\
\text { acting }\end{array}$ \\
\hline 7 & $39(F)$ & $\mathrm{EH} B D C$ & Cyst & Tail, body & Multiple cysts & No & $\begin{array}{c}\text { Bicornuate } \\
\text { unicollis }\end{array}$ & Short-acting \\
\hline 8 & $17(\mathrm{M})$ & $\mathrm{N}$ & $\mathrm{N}$ & Tail, body ${ }^{g}$ & $\begin{array}{l}\text { Multiple cysts in } \\
\text { right kidney }\end{array}$ & No & - & None \\
\hline 11 & $37(F)$ & $\mathrm{IH} B D C$ & N & Tail, body & Multiple cysts & No & $\mathrm{N}$ & Combined \\
\hline 12 & $22(\mathrm{M})$ & $\mathrm{N}$ (gallbladder $\left.{ }^{h}\right)$ & N & Tail $^{h}$ & Multiple cysts & No & - & None $^{h}$ \\
\hline 13 & $30(F)$ & $\mathrm{N}^{i}$ & $\mathrm{~N}$ & Tail, body & Multiple cysts & $\begin{array}{l}\text { Kidney } \\
\text { transplantation }\end{array}$ & $\begin{array}{c}\text { Bicornuate } \\
\text { unicollis }\end{array}$ & $\begin{array}{l}\text { Intermediate- } \\
\text { acting }\end{array}$ \\
\hline 14 & $68(F)$ & $\mathrm{EH}$ and $\mathrm{IH} \mathrm{BDC}^{j}$ & $\mathrm{~N}$ & Tail $^{k}$ & Multiple cysts & Mild & $\mathrm{N}$ & Long-acting \\
\hline
\end{tabular}

Abbreviations: $\mathrm{EH}$, extrahepatic; F, female; $I H$, intrahepatic; $M$, male; $N$, normal; NA, not available; Rl, renal insufficiency.

${ }^{a}$ At the time of MRI.

${ }^{b}$ At the time of MRI, estimated glomerular filtration rate (millimeters per minute divided by $1.73 \mathrm{~m}^{2}$ ): mild, 60 to 89 ; moderate, 30 to 59 ; severe, 15 to 29 ; end-stage renal disease, $<15$.

'Long-acting insulin started at 14 years.

${ }^{d}$ A splenic cyst.

e Later progressed to moderate.

${ }^{f}$ Later progressed to end-stage renal disease, renal transplantation.

${ }^{g}$ Intraductal papillary mucinous neoplasialike cystic dilatations of the pancreatic branch ducts.

${ }^{h}$ Adenomyomatosis of the gallbladder and pancreas divisum was observed. The horizontal duodenum did not cross the midline at its normal position, a finding suggestive of malrotation. Normal glucose tolerance in oral glucose tolerance test.

${ }^{i}$ After renal transplantation, cholestatic episode caused by adenomatous tissue near ampulla of Vater.

${ }^{j}$ In addition to the dilated biliary ducts, adenomyomatosis of the gallbladder was observed.

${ }^{k} \mathrm{~A}$ few punctate calcifications in the pancreatic parenchyma were detectable on computed tomography imaging.

proximal intrahepatic bile ducts caused by a papillary tumorlike mass, which by subsequent ERCP imaging and biopsies proved to be benign adenoma.

The liver parenchyma appeared normal in all cases; one patient had a small subcapsular cyst, which is a common incidental finding in the general population as well (Table 1). Nevertheless, seven patients had abnormal serum ALT levels, which were generally less than twice the upper reference limit. However, after major abdominal surgery (patient no. 1) or renal transplantation (patients no. 6 and 13), ALT had transiently exceeded the upper reference limit by 24 -fold.

Most patients (12 of 14) had a hypoplastic pancreas: nine had a hypoplasia of the body and tail of the pancreas, whereas three patients lacked only the tail (Table 1; Fig. 3). One patient had small calcifications in the pancreatic parenchyma. The radiological findings did not correlate with the severity of diabetes. Two patients with normal pancreas on imaging had mild diabetes without treatment (age 10 and 27 years; HbA1c, 32 and $36 \mathrm{mmol} / \mathrm{mol}$, respectively). Of the 12 patients with hypoplastic pancreatic findings, the degree of glycemia varied from normal (one 22-year-old patient had $\mathrm{HbA} 1 \mathrm{c}$ of $35 \mathrm{mmol} / \mathrm{mol}$ ) to diabetic, and therapy ranged from none in four patients (age 12 to 22 years; $\mathrm{HbA} 1 \mathrm{c}, 33$ to $44 \mathrm{mmol} / \mathrm{mol}$ ) to insulin in eight patients (age 14 to 68 years; HbA1c, 35 to 92; median HbA1c, 48 mmol/mol) (Table 1).

The pancreatic duct was of normal caliber in all patients, albeit shorter than usual in patients who had pancreatic hypoplasia. Patient no. 12 had the normal variant of pancreas divisum, in which the ventral and dorsal pancreatic ducts have not fused during embryonic development (Table 1). Patients no. 7 and 14 had small cystic dilatations of the pancreatic branch ducts; the MRI 

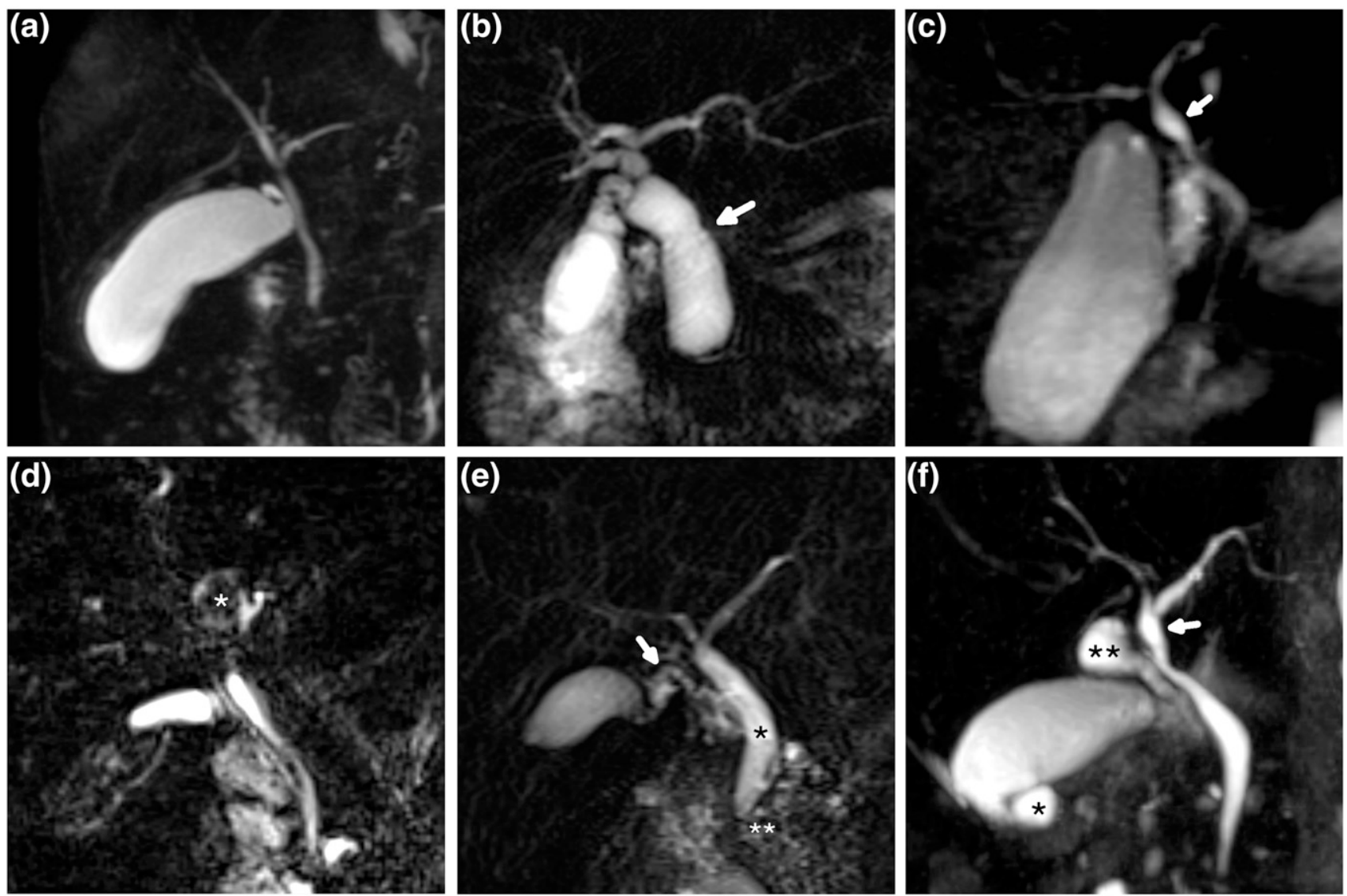

Figure 1. Maximum-intensity projection images of the MRCP studies depicting the extrahepatic bile ducts and the main intrahepatic ducts for the five patients with BDCs. All fluid is seen as white. (a) Patient no. 9, with normal extrahepatic bile ducts and gallbladder for reference. (b) Patient no. 1, with BDC (arrow) affecting the common bile duct (type 1a by the Todani classification). The dilatation impairs bile drainage, resulting in widened bile ducts distal to the cyst. (c) Patient no. 4, with a fusiform BDC of the common hepatic duct (arrow). The common bile duct and the intrahepatic ducts are of normal caliber (Todani classification not applicable). (d) Patient no. 5, with an intrahepatic, 25-mm BDC (asterisk) communicating with the left main bile duct. The debris inside the cyst is seen as dark. The biliary system was otherwise normal (Todani classification not applicable). (e) Patient no. 7, with a fusiform BDC (width, $9 \mathrm{~mm}$ ) of the entire extrahepatic bile ducts (asterisk) (Todani 1c). In addition, the cystic duct (arrow) insertion to the common bile duct is abnormally low and medial (double asterisk). The intrahepatic bile ducts are normal. (f) Patient no. 11, with multiple bile duct anomalies as well as a fusiform BDC of the common hepatic duct, similar to that of patient no. 4 (arrow). A diverticlelike BDC of the cystic duct (asterisk) and another diverticle-shaped BDC extending from the gallbladder fundus (double asterisk) (Todani classification not applicable).

findings resembled those of intraductal papillary mucinous neoplasia (Fig. 3).

With renal cysts observed in all but one patient, the radiological findings did not correlate with the severity of renal insufficiency; in eight of $14(57 \%)$ patients, the renal function appeared to be normal, whereas six patients had renal insufficiency of some degree (Table 1). Uterine malformations were common (five of the $11 \mathrm{fe}$ male patients) (Table 1).

Of 12 patients with data for magnesium concentrations, $10(83 \%)$ have had hypomagnesemia at some stage of the follow-up (Fig. 4), but it was symptomatic in only two patients (one had muscle cramps and one had hypokalemia, despite replacement with potassium chloride). The average (mean of individual medians) concentration of magnesium was $0.66 \mathrm{mmol} / \mathrm{L}$ and the lowest concentration was $0.36 \mathrm{mmol} / \mathrm{L}$ (reference range $\geq 0.70 \mathrm{mmol} / \mathrm{L}$ ). Uric acid concentration was, at least occasionally, elevated in nine of the 14 (64\%) patients, but only one had developed symptomatic gout. The highest uric acid concentration was 1.6 times the upper limit of normal (Fig. 4). As suggested by Clissold (a)

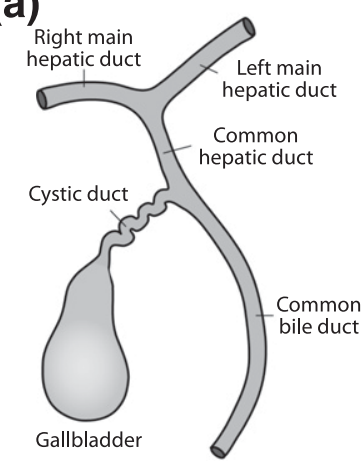

(b)

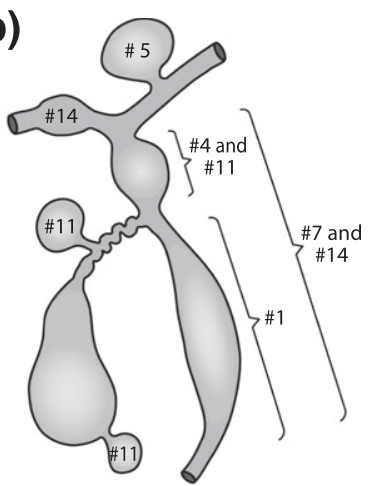

Figure 2. A schematic drawing of the (a) normal bile duct system and (b) various anomalies we observed in our patients. 

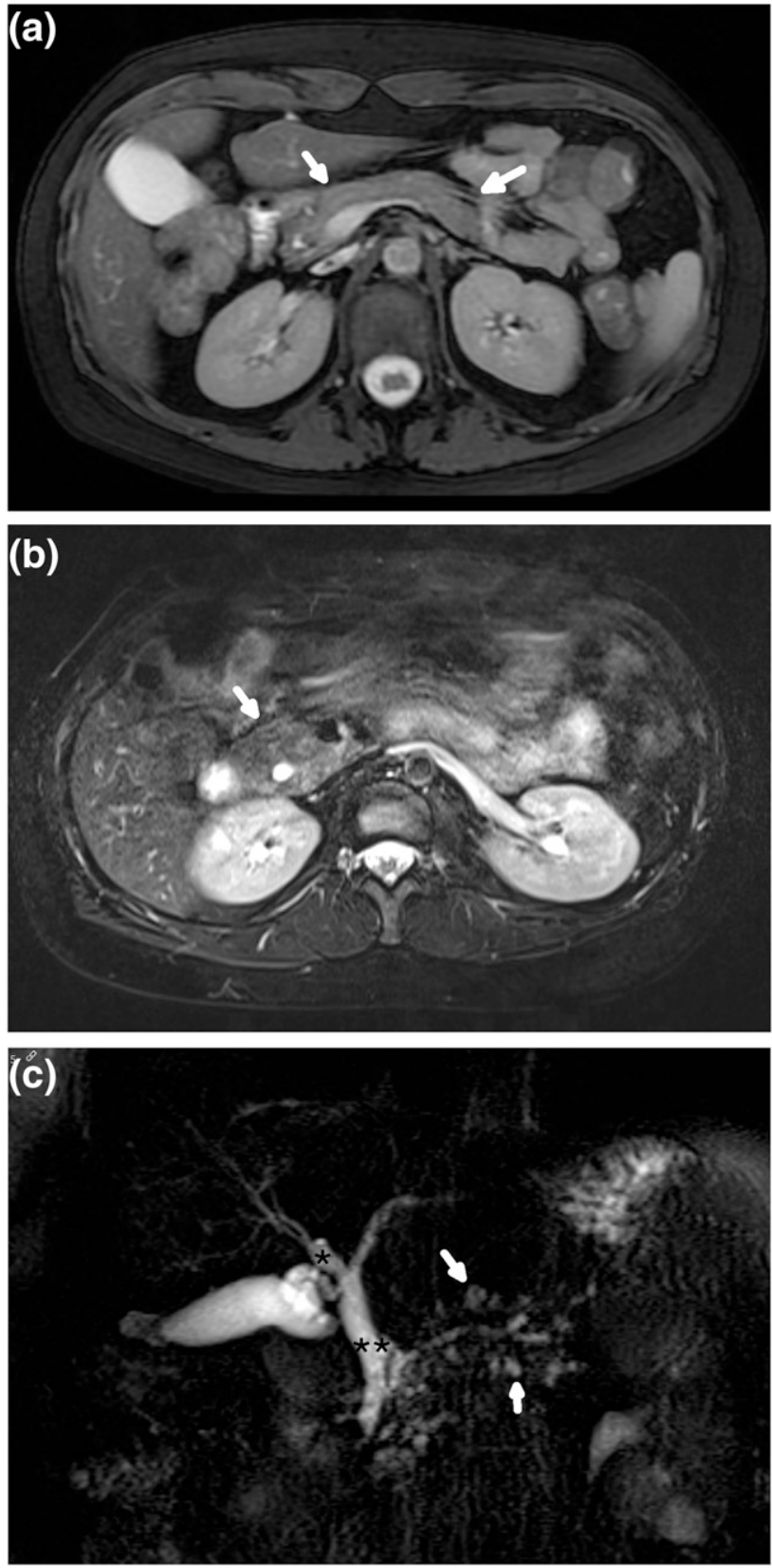

Figure 3. T2-weighted axial MRI scans of the pancreas with $(a, b)$ fat saturation and (c) a maximum-intensity projection image of the MRCP images. Aplasia of the pancreatic body and tail was observed in nine patients. One of these patients had cystic dilatations of the pancreatic branch ducts. (a) Patient no. 9, with normal pancreas (arrows). (b) Patient no. 7, in whom only the pancreatic head and uncinate process can be observed (arrow). (c) Patient no. 14, with small cystic dilatations of the pancreatic branch ducts (arrows) consistent with branch duct intrapancreatic mucinous neoplasia. A fusiform BDC of the extrahepatic bile ducts in their entirety (double asterisk) and the right main bile duct (asterisk), consistent with Todani classification type $4 a$, is also seen.

et al. (21), patients with whole-allele deletions of $H N F 1 B$ seemed to have lower magnesium concentrations, and patients with intragenic mutations had higher uric acid concentrations, but the differences were not statistically significant (Fig. 4).

\section{Discussion}

Besides confirming the frequent occurrence of pancreatic hypoplasia, contrast-enhanced MRI and MRCP revealed BDCs in six of 14 HNF1B carriers, which clearly exceeds the reported 1:13,000 to 1:150,000 prevalence in Western populations (30-32). Together with the developmental role of $H N F 1 B$ in biliary organogenesis $(1,3,5)$ and case reports on cholestasis in mutation carriers (23-25), our report confirms a biliary phenotype in human $H N F 1 B$ disease and shows that such a phenotype is more prevalent than previously reported. Do these findings have clinical implications?

In patients with $H N F 1 B$, the combination of reduced $\beta$-cell mass (12 of the 14 patients had pancreatic hypoplasia), associated with functional abnormalities in insulin secretion (10), may precipitate diabetes in nondiabetic carriers, or worsen the hyperglycemia in diabetic carriers at initiation of immunosuppressive therapy. Because many immunosuppressive agents (calcineurin inhibitors, mTOR inhibitors, and steroids) inhibit insulin transcription and/or secretion, and steroids decrease insulin sensitivity (33), careful monitoring of plasma glucose after transplantation is fundamental, irrespective of pretransplantation diabetes status of patients with HNF1B. Not surprisingly, the two patients with a kidney transplantation (nos. 6 and 13) showed deterioration of glycemic control during posttransplantation treatment.

The multiple observations of BDCs or choledochal cysts, which are rare cystic or fusiform dilatations of the extrahepatic and/or intrahepatic biliary ducts, was an unexpected finding. Yet, the pathophysiology of BDCs is unclear. The most prevalent theory states that an anomalous pancreaticobiliary junction (APBJ) is associated with reflux of the pancreatic juice, eventually leading to a BDC (30-32). We did not observe an APBJ in any patient (data not shown). Furthermore, primary strictures of the common bile duct may, in part, contribute to the dilatation of the bile ducts (32). Alternatively, BDCs may be ductal plate malformations (34), a theory supported by reports on ductal plate malformations in some neonatal patients with HNF1B (23-26), as well as evidence in mice that inactivation of $H N F 1 B$ results in such malformations (35).

Traditionally, BDCs are classified according to the classification system proposed by Todani et al (36), but this has been criticized for its complexity and the need for additions, given that not all types of cysts are covered [as reviewed by Katabathina et al (31)]. Only three of our patients' BDCs had typical morphology for any Todani class. Previously, BDCs were mostly diagnosed in children with a triad of jaundice, abdominal pain, and 

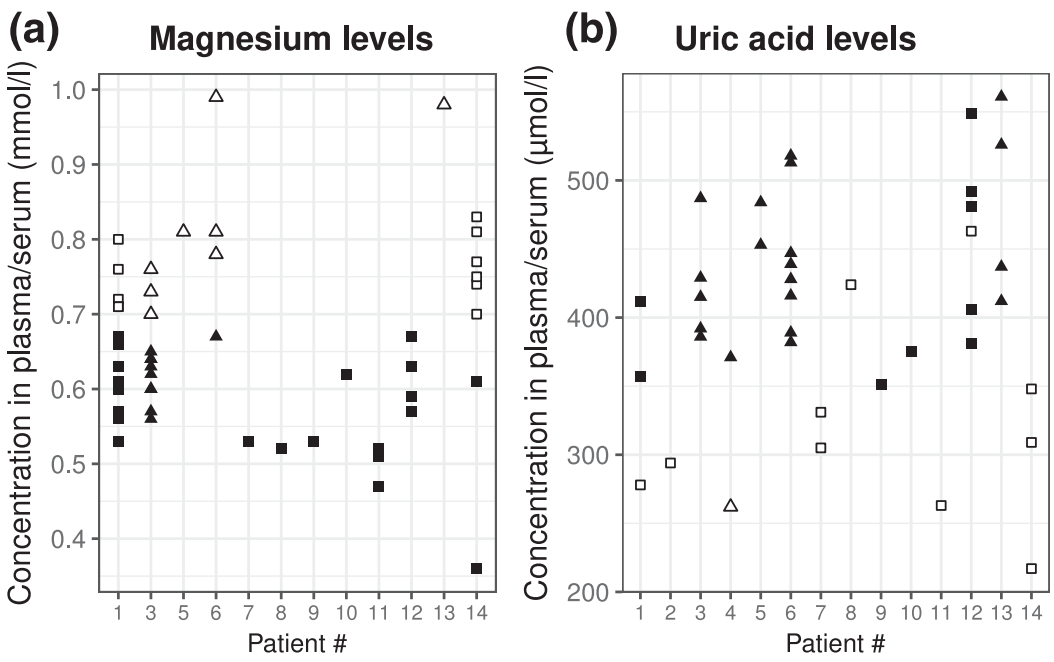

Figure 4. The figure shows all available (a) magnesium and (b) uric acid concentrations for the patients. A value within the reference range is shown with an open symbol, and a value outside the reference range is shown with a filled symbol. The lower reference range for magnesium is $0.70 \mathrm{mmol} / \mathrm{L}$, and the upper reference limit for uric acid for adult female patients is $350 \mu \mathrm{mol} / \mathrm{L}$ (the reference range for uric acid is age and sex dependent). Magnesium values after initiation of magnesium substitution, and uric acid values after kidney transplantation or initiation of allopurinol treatment, are excluded. Values from patients with whole-allele deletions of HNF1B are depicted with squares, and values from patients with intragenic mutations are depicted with with triangles.

warrants at least careful consideration of pros and cons of surgically excising the BDCs, given that the surgery usually includes a Roux-en-Y hepaticojejunostomy, with partial removal of the head of pancreas $(37,38)$, which will potentially lead to deterioration of endocrine and exocrine pancreatic functions that are already impaired in patients with HNF1B. On the other hand, there is no way to accurately predict the individual risk of malignancy, and the biliary anomalies might result in technical challenges in ERCP and increased risk for complications when collecting brush cytology. Indeed, there were technical problems in both of our patients who had undergone ERCP.

In accord with previous reports of increased levels of ALT and aspartate aminotransferase in up to $50 \%$ to $75 \%$ of patients with $H N F 1 B$ without ap-

palpable mass, but after advances in modern diagnostic imaging, up to $36 \%$ of the affected are adults with incidental BDCs or with nonspecific symptoms (30-32). Indeed, excluding posttransplantation and postoperative complications, our cohort included only one patient with a medical history of unspecific, occasional abdominal symptoms. BDCs can result in various complications, including biliary stones, cholangitis, pancreatitis, portal hypertension, liver cirrhosis and fibrosis, as well as spontaneous cyst ruptures. The most severe complication, however, is the risk for cholangiocarcinoma, which increases from $0.7 \%$ in children to as high as $15 \%$ to $20 \%$ in adults $(30,37)$. Other malignancies (particularly gallbladder cancer) have also been associated with BDCs (30).

Because of their premalignant nature, the majority of extrahepatic BDCs are surgically excised $(37,38)$. An increasing number of incidental BDCs has led to a debate as to whether only symptomatic or high-risk patients should undergo surgery (30). Unfortunately, an individual risk assessment is not possible. Apart from the association between APBJs and gallbladder cancer (30), no structural or biochemical risk factor has been identified. Is the risk of malignancy of $H N F 1 B$-related BDCs similar to the risk of other BDCs? A previously described patient with $H N F 1 B$ and neonatal cholestasis had two paternal family members with liver cirrhosis and liver cancer, but information on their mutation status or the nature of the cancer was not available (39). The frequent finding of hypoplastic pancreas in $H N F 1 B$ carriers parent liver disease [as reviewed by Chen et al (7)], half of our patients had slightly elevated serum ALT concentrations. Because liver biopsies have rarely been performed and all reported patient series have been small, the etiology remains obscure. Only two of our patients (nos. 6 and 13) were known to have had cholestatic episodes, but in both cases, cholestasis developed after renal transplantation and during immunosuppressive treatment with calcineurin inhibitors. In vitro, calcineurin inhibitors downregulate $H N F 1 B$ gene transcription and translation, and the downregulation of the nonmutated allele has been associated with posttransplantation cholestasis (28). Thus, a pretransplantation diagnosis of HNF1B disease warrants careful follow-up of hepatic and biliary laboratory parameters, which is crucial for an early diagnosis of more severe forms of cholestasis.

\section{Conclusions}

Imaging with contrast-enhanced MRI and MRCP revealed BDCs, also known as choledochal cysts, in six of 14 HNF1B carriers. It is unknown whether these choledochal cysts confer a similar risk for cholangiocarcinoma as BDCs in general. On the basis of this small series of patients, recommendations for routine screening of patients with $H N F 1 B$ mutations cannot be given. Further studies in larger patient series as well as genetic testing of HNF1B mutations in individuals with BDCs that have resulted in cholangiocarcinoma are needed. In any case, surgical resection involving partial 
removal of the head of pancreas poses a significant risk for the deterioration of insulin secretion in these patients, who generally already lack the body and tail of the pancreas. Finally, clinical evaluation of the other disease manifestations associated with $H N F 1 B$ mutations and/or genetic testing should be considered in patients with BDCs.

\section{Acknowledgments}

We thank Dr. Satu Vehkavaara, Dr. Virpi Sipilä, and Dr. Tuula Pekkarinen for the referral of three of the patients. The Botnia Study has also been supported by grants from the Sigrid Juselius Foundation, Foundation for Life and Health in Finland, Finnish Medical Society, Ollqvist Foundation, Närpes Health Care Foundation, as well as by the Municipal Heath Care Center and Hospital in Jakobstad and Health Care Centers in Vasa, Närpes, and Korsholm. The skillful assistance of the Botnia Study Group is gratefully acknowledged.

Address all correspondence and requests for reprints to: Tiinamaija Tuomi, MD, Endocrinology, Abdominal Center, Helsinki University Hospital, PO Box 340, FIN-00029 HUS, Helsinki, Finland. E-mail: tiinamaija.tuomi@hus.fi.

This work was supported by the Folkhalsan Research Foundation, Helsinki University Central Hospital Research Foundation, Finnish Diabetes Research Foundation, Finnish Medical Society, Foundation for Pediatric Research, Ahokas Foundation, and the Diabetes Wellness Foundation.

Disclosure Summary: The authors have nothing to disclose.

\section{References}

1. Coffinier C, Thépot D, Babinet C, Yaniv M, Barra J. Essential role for the homeoprotein vHNF1/HNF1beta in visceral endoderm differentiation. Development. 1999;126(21):4785-4794.

2. Haumaitre C, Barbacci E, Jenny M, Ott MO, Gradwohl G, Cereghini S. Lack of TCF2/vHNF1 in mice leads to pancreas agenesis. Proc Natl Acad Sci USA. 2005;102(5):1490-1495.

3. Lokmane L, Haumaitre C, Garcia-Villalba P, Anselme I, SchneiderMaunoury S, Cereghini S. Crucial role of vHNF1 in vertebrate hepatic specification. Development. 2008;135(16):2777-2786.

4. Kato N, Motoyama T. Hepatocyte nuclear factor-1beta(HNF1beta) in human urogenital organs: its expression and role in embryogenesis and tumorigenesis. Histol Histopathol. 2009; 24(11):1479-1486.

5. Strazzabosco M, Fabris L. Development of the bile ducts: essentials for the clinical hepatologist. J Hepatol. 2012;56(5):1159-1170.

6. Bingham C, Bulman MP, Ellard S, Allen LI, Lipkin GW, Hoff WG, Woolf AS, Rizzoni G, Novelli G, Nicholls AJ, Hattersley AT. Mutations in the hepatocyte nuclear factor- $1 \beta$ gene are associated with familial hypoplastic glomerulocystic kidney disease. Am J Hum Genet. 2001;68(1):219-224.

7. Chen Y-Z, Gao Q, Zhao X-Z, Chen YZ, Bennett CL, Xiong XS, Mei CL, Shi YQ, Chen XM. Systematic review of TCF2 anomalies in renal cysts and diabetes syndrome/maturity onset diabetes of the young type 5. Chin Med J (Engl). 2010;123(22):3326-3333.

8. Horikawa Y, Iwasaki N, Hara M, Furuta H, Hinokio Y, Cockburn BN, Lindner T, Yamagata K, Ogata M, Tomonaga O, Kuroki H, Kasahara T, Iwamoto Y, Bell GI. Mutation in hepatocyte nuclear factor-1 beta gene (TCF2) associated with MODY. Nat Genet. 1997;17(4):384-385.
9. Clissold RL, Hamilton AJ, Hattersley AT, Ellard S, Bingham C. HNF1B-associated renal and extra-renal disease-an expanding clinical spectrum. Nat Rev Nephrol. 2015;11(2):102-112.

10. Brackenridge A, Pearson ER, Shojaee-Moradie F, Hattersley AT, Russell-Jones D, Umpleby AM. Contrasting insulin sensitivity of endogenous glucose production rate in subjects with hepatocyte nuclear factor-1beta and -1alpha mutations. Diabetes. 2006;55(2): 405-411.

11. Haldorsen IS, Vesterhus M, Raeder H, Jensen DK, Søvik O, Molven A, Njølstad PR. Lack of pancreatic body and tail in HNF1B mutation carriers. Diabet Med. 2008;25(7):782-787.

12. Adalat S, Woolf AS, Johnstone KA, Wirsing A, Harries LW, Long DA, Hennekam RC, Ledermann SE, Rees L, van't Hoff W, Marks SD, Trompeter RS, Tullus K, Winyard PJ, Cansick J, Mushtaq I, Dhillon HK, Bingham C, Edghill EL, Shroff R, Stanescu H, Ryffel GU, Ellard S, Bockenhauer D. HNF1B mutations associate with hypomagnesemia and renal magnesium wasting. J Am Soc Nephrol. 2009;20(5):1123-1131.

13. Bingham C, Ellard S, van't Hoff WG, Simmonds HA, Marinaki AM, Badman MK, Winocour PH, Stride A, Lockwood CR, Nicholls AJ, Owen KR, Spyer G, Pearson ER, Hattersley AT. Atypical familial juvenile hyperuricemic nephropathy associated with a hepatocyte nuclear factor-1beta gene mutation. Kidney Int. 2003;63(5):1645-1651.

14. Iwasaki N, Ogata M, Tomonaga O, Kuroki H, Kasahara T, Yano $\mathrm{N}$, Iwamoto $\mathrm{Y}$. Liver and kidney function in Japanese patients with maturity-onset diabetes of the young. Diabetes Care. 1998;21(12): 2144-2148.

15. Lindner TH, Njolstad PR, Horikawa Y, Bostad L, Bell GI, Sovik O. A novel syndrome of diabetes mellitus, renal dysfunction and genital malformation associated with a partial deletion of the pseudo-POU domain of hepatocyte nuclear factor-1beta. Hum Mol Genet. 1999;8(11):2001-2008.

16. Oram RA, Edghill EL, Blackman J, Taylor MJ, Kay T, Flanagan SE, Ismail-Pratt I, Creighton SM, Ellard S, Hattersley AT, Bingham C. Mutations in the hepatocyte nuclear factor-1 $\beta$ (HNF1B) gene are common with combined uterine and renal malformations but are not found with isolated uterine malformations. Am J Obstet Gynecol. 2010;203(4):364.e1-364.e5.

17. Bingham C, Ellard S, Cole TRP, Jones KE, Allen LI, Goodship JA, Goodship TH, Bakalinova-Pugh D, Russell GI, Woolf AS, Nicholls AJ, Hattersley AT. Solitary functioning kidney and diverse genital tract malformations associated with hepatocyte nuclear factor1beta mutations. Kidney Int. 2002;61(4):1243-1251.

18. Montoli A, Colussi G, Massa O, Caccia R, Rizzoni G, Civati G, Barbetti F. Renal cysts and diabetes syndrome linked to mutations of the hepatocyte nuclear factor-1 beta gene: description of a new family with associated liver involvement. Am J Kidney Dis. 2002; 40(2):397-402.

19. Tjora E, Wathle G, Erchinger F, Engjom T, Molven A, Aksnes L, Haldorsen IS, Dimcevski G, Raeder H, Njølstad PR. Exocrine pancreatic function in hepatocyte nuclear factor $1 \beta$-maturity-onset diabetes of the young (HNF1B-MODY) is only moderately reduced: compensatory hypersecretion from a hypoplastic pancreas. Diabet Med. 2013;30(8):946-955.

20. Ferrè S, Bongers EMHF, Sonneveld R, Cornelissen EA, van der Vlag J, van Boekel GA, Wetzels JF, Hoenderop JG, Bindels RJ, Nijenhuis T. Early development of hyperparathyroidism due to loss of PTH transcriptional repression in patients with HNF1 $\beta$ mutations? J Clin Endocrinol Metab. 2013;98(10):4089-4096.

21. Clissold RL, Shaw-Smith C, Turnpenny P, Bunce B, Bockenhauer D, Kerecuk L, Waller S, Bowman P, Ford T, Ellard S, Hattersley AT, Bingham C. Chromosome 17q12 microdeletions but not intragenic HNF1B mutations link developmental kidney disease and psychiatric disorder. Kidney Int. 2016;90(1):203-211.

22. Coffinier C, Gresh L, Fiette L, Tronche F, Schütz G, Babinet C, Pontoglio M, Yaniv M, Barra J. Bile system morphogenesis defects and liver dysfunction upon targeted deletion of HNF1beta. Development. 2002;129(8):1829-1838. 
23. Beckers D, Bellanné-Chantelot C, Maes M. Neonatal cholestatic jaundice as the first symptom of a mutation in the hepatocyte nuclear factor-1 $\beta$ gene (HNF-1 $\beta$ ). J Pediatr. 2007;150(3):313-314.

24. Raile K, Klopocki E, Holder M, Wessel T, Galler A, Deiss D, Müller D, Riebel T, Horn D, Maringa M, Weber J, Ullmann R, Grüters A. Expanded clinical spectrum in hepatocyte nuclear factor $1 \mathrm{~b}$ maturity-onset diabetes of the young. J Clin Endocrinol Metab. 2009;94(7):2658-2664.

25. Kotalova R, Dusatkova P, Cinek O, Dusatkova L, Dedic T, Seeman T, Lebl J, Pruhova S. Hepatic phenotypes of HNF1B gene mutations: a case of neonatal cholestasis requiring portoenterostomy and literature review. World J Gastroenterol. 2015;21(8): 2550-2557.

26. Raynaud P, Tate J, Callens C, Cordi S, Vandersmissen P, Carpentier R, Sempoux C, Devuyst O, Pierreux CE, Courtoy P, Dahan K, Delbecque K, Lepreux S, Pontoglio M, Guay-Woodford LM, Lemaigre FP. A classification of ductal plate malformations based on distinct pathogenic mechanisms of biliary dysmorphogenesis. Hepatology. 2011;53(6):1959-1966.

27. Roelandt P, Antoniou A, Libbrecht L, Van Steenbergen W, Laleman W, Verslype C, Van der Merwe S, Nevens F, De Vos R, Fischer E, Pontoglio M, Lemaigre F, Cassiman D. HNF1B deficiency causes ciliary defects in human cholangiocytes. Hepatology. 2012;56(3): 1178-1181.

28. Faguer S, Esposito L, Casemayou A, Pirson Y, Decramer S, Cartery C, Hazzan M, Garrigue V, Roussey G, Cointault O, Ho T, Merville P, Devuyst O, Gourdy P, Chassaing N, Bascands JL, Kamar N, Schanstra JP, Rostaing L, Chauveau D. Calcineurin inhibitors downregulate HNF-1 $\beta$ and may affect the outcome of HNF1B patients after renal transplantation. Transplantation. 2016;100(9): 1970-1978.

29. Todani T, Watanabe Y, Toki A, Morotomi Y. Classification of congenital biliary cystic disease: special reference to type Ic and IVA cysts with primary ductal stricture. J Hepatobiliary Pancreat Surg. 2003;10(5):340-344.
30. Sastry AV, Abbadessa B, Wayne MG, Steele JG, Cooperman AM. What is the incidence of biliary carcinoma in choledochal cysts, when do they develop, and how should it affect management? World J Surg. 2015;39(2):487-492.

31. Katabathina VS, Kapalczynski W, Dasyam AK, Anaya-Baez V, Menias CO. Adult choledochal cysts: current update on classification, pathogenesis, and cross-sectional imaging findings. Abdom Imaging. 2015;40(6):1971-1981.

32. Lewis VA, Adam SZ, Nikolaidis P, Wood C, Wu JG, Yaghmai V, Miller FH. Imaging of choledochal cysts. Abdom Imaging. 2015; 40(6):1567-1580.

33. Langsford D, Dwyer K. Dysglycemia after renal transplantation: Definition, pathogenesis, outcomes and implications for management. World J Diabetes. 2015;6(10):1132-1151.

34. Summerfield JA, Nagafuchi Y, Sherlock S, Cadafalch J, Scheuer PJ. Hepatobiliary fibropolycystic diseases. A clinical and histological review of 51 patients. J Hepatol. 1986;2(2):141-156.

35. Raynaud P, Carpentier R, Antoniou A, Lemaigre FP. Biliary differentiation and bile duct morphogenesis in development and disease. Int J Biochem Cell Biol. 2011;43(2):245-256.

36. Todani T, Watanabe Y, Narusue M, Tabuchi K, Okajima K. Congenital bile duct cysts: Classification, operative procedures, and review of thirty-seven cases including cancer arising from choledochal cyst. Am J Surg. 1977;134(2):263-269.

37. Jabłońska B. Biliary cysts: etiology, diagnosis and management. World J Gastroenterol. 2012;18(35):4801-4810.

38. Cerwenka H. Bile duct cyst in adults: interventional treatment, resection, or transplantation? World J Gastroenterol. 2013;19(32): 5207-5211.

39. Kitanaka S, Miki Y, Hayashi Y, Igarashi T. Promoter-specific repression of hepatocyte nuclear factor (HNF)-1 beta and HNF-1 alpha transcriptional activity by an HNF-1 beta missense mutant associated with type 5 maturity-onset diabetes of the young with hepatic and biliary manifestations. J Clin Endocrinol Metab. 2004; 89(3):1369-1378. 